\title{
Shedding light on pediatric diseases: multispectral optoacoustic tomography at the doorway to clinical applications
}

\author{
Adrian P. Regensburger ${ }^{1}$, Alexandra L. Wagner ${ }^{1}$, Jing Claussen ${ }^{1}$, Maximilian J. Waldner ${ }^{2}$ and Ferdinand Knieling ${ }^{1 *}$
}

\begin{abstract}
Optoacoustic imaging (OAI), or photoacoustic imaging (PAI), has fundamentally influenced basic science by providing high-resolution visualization of biological mechanisms. With the introduction of multispectral optoacoustic tomography (MSOT), these technologies have now moved closer to clinical applications. MSOT utilizes short-pulsed near-infrared laser light to induce thermoelastic expansion in targeted tissues. This results in acoustic pressure waves, which are used to resolve specific endo- and exogenous chromophores. Especially in the pediatric population, this non-invasive imaging approach might hold fundamental advantages compared to conventional cross-sectional imaging modalities. As this technology allows the visualization of quantitative molecular tissue composition at high spatial resolution non-invasively in sufficient penetration depth, it paves the way to personalized medicine in pediatric diseases.
\end{abstract}

\section{Technologic background}

Up to now, ultrasound has played a central role in pediatric diagnostics. Due to its neglectable risk profile and easy availability, it is the diagnostic tool of choice for a variety of different indications [1-4]. As current state of the art ultrasound technologies, such as contrast-enhanced ultrasound (CEUS) do, on the one hand, allow functional flow-based tissue analysis $[5,6]$, but they essentially require the application of "acoustic" labels on the other. In addition, when compared to new cross-sectional imaging techniques (e.g., PET-CT), ultrasound is limited in visualizing subcellular composition of tissues and therefore diagnostic possibilities. All of this led to the development of new functional and molecular, non-invasive imaging approaches in recent years.

In this regard, multispectral optoacoustic tomography (MSOT) is rapidly evolving as one promising key

\footnotetext{
*Correspondence: ferdinand.knieling@uk-erlangen.de

'Pediatric Experimental and Translational Imaging Laboratory (PETI-Lab),

Department of Pediatrics and Adolescent Medicine,

Friedrich-Alexander-University (FAU) Erlangen-Nuremberg, Loschgestraße 15,

91054 Erlangen, Germany

Full list of author information is available at the end of the article
}

technology. MSOT utilizes short-pulsed laser light in the near- and extended near-infrared range (NIR/exNIR) for tissue illumination. As light in these wavelengths has fewer tissue absorption, it enables deeper tissue penetration. The NIR is typically represented in the wavelength between 700 and $900 \mathrm{~m}$ followed by extend NIR (exNIR)/NIR II window around 900-1600 nm. In OAI, this light is absorbed by tissue molecules and converted into acoustic pressure waves, which can be recorded and formed into optoacoustic images. In the NIR, endogenous absorbers such as deoxyhemoglobin, oxyhemoglobin, and melanin possess distinct absorption spectra, which gives them a unique signature in MSOT $[7,8]$. In the exNIR, further absorption peaks for lipids, water, and collagens can be found [9]. Multispectral imaging, e.g., the utilization of different wavelengths, enables the quantification and spatial resolution of these molecules in MSOT images [10]. A translatable system (MSOT Acuity, iThera Medical GmbH, Munich, Germany) comprises a tunable optical parametric oscillator (OPO) that is pumped by an Nd:YAG laser to provide exact excitation pulses. The pulse energy $(30 \mathrm{~mJ}$ peak at $730 \mathrm{~nm})$ is as low as to adhere with ANSI limits of maximum 
permissible exposure (MPE) of the skin. Using different center frequencies, the resolution ranges between 290 $\mu \mathrm{m}(4 \mathrm{MHz})$ and $345 \mu \mathrm{m}(3 \mathrm{MHz})$, respectively. The same imaging probe can then detect the delivered light and resulting sound waves. The probe is comparable to standard ultrasound systems (Fig. 1). In order to translate the use in clinical scenarios, the technique has been fused with conventional ultrasound imaging, called reflectance ultrasound computed tomography (RUCT) [11]. For RUCT generation, an ultrasound imaging platform is used, which synchronizes ultrasound and optoacoustic image streams [12].

\section{Current clinical applications}

OAI has so far been used in a number of various clinical applications; selected studies are summarized in Table 1 . The strength of MSOT is the ability to quantify endogenous chromophores, of which hemoglobin is well known and best absorbing in human tissues. Traditionally, a wavelength of $700 \mathrm{~nm}$ is used to detect the peak

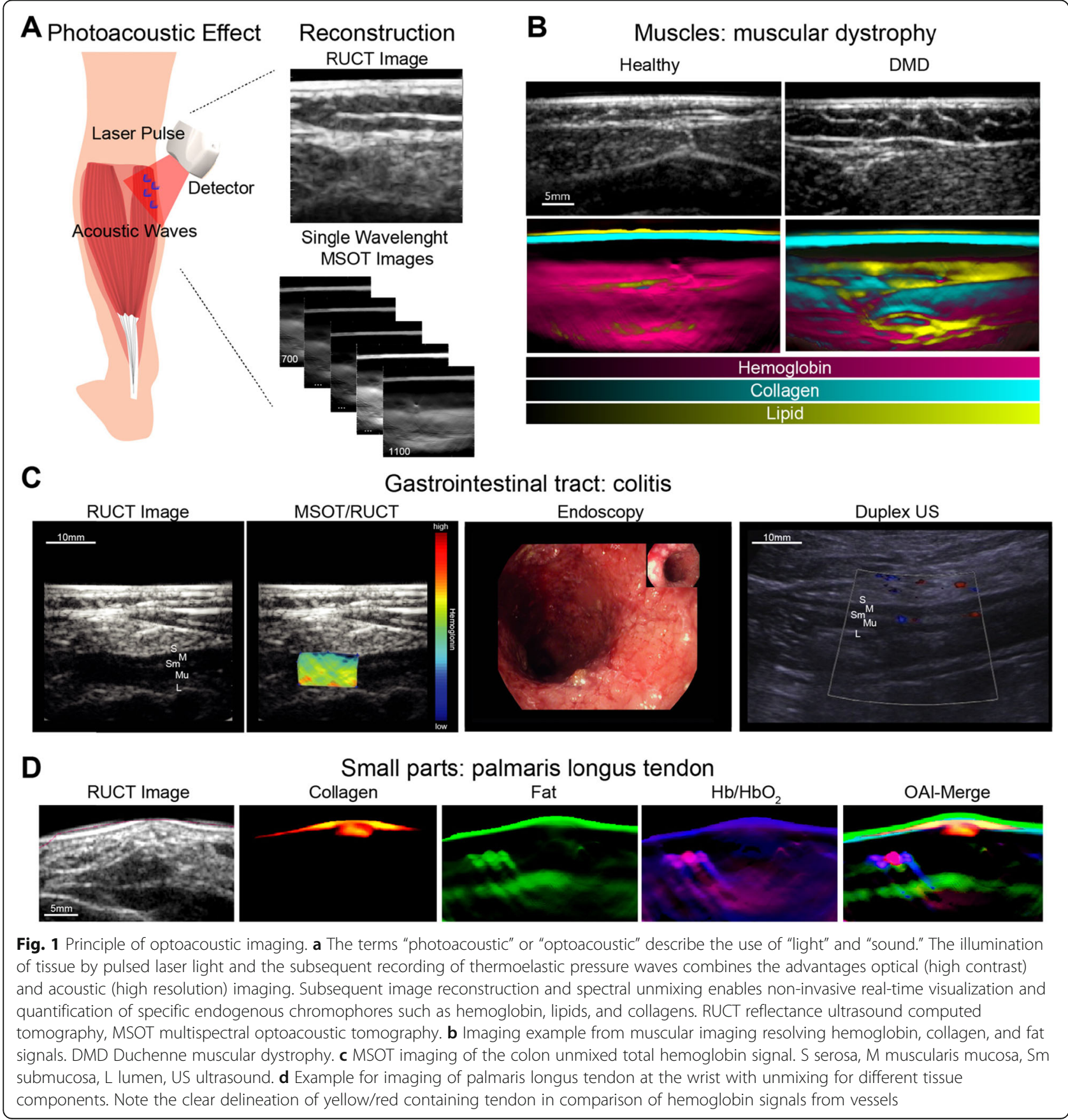


Table 1 Selected clinical OAl studies

\begin{tabular}{|c|c|c|c|c|}
\hline Anatomical region/organ & Chromophores & Wavelength $(\mathrm{nm})$ & Clinical output & References \\
\hline Non-melanoma skin cancer & $\mathrm{Hb}_{\mathrm{R}}, \mathrm{HbO}_{2}$, melanin & $\begin{array}{l}700,715,730,760,780,790, \\
800,825,850,900\end{array}$ & $\begin{array}{l}\text { Mapping and visualization of } \\
\text { skin cancer }\end{array}$ & {$[13,14]$} \\
\hline Skin (hair follicles) & $\mathrm{Hb}_{\mathrm{R}}, \mathrm{HbO}_{2}$, melanin, lipids & $660-1300$ & $\begin{array}{l}\text { Measurement of the structural and } \\
\text { physiological features of intact hair } \\
\text { follicles }\end{array}$ & [15] \\
\hline \multirow[t]{7}{*}{ Vasculature } & $\mathrm{Hb}_{\mathrm{R}}, \mathrm{HbO}_{2}$ & $700-850$ & $\begin{array}{l}\text { Noninvasive diagnosis and monitoring } \\
\text { of vascular malformations }\end{array}$ & [16] \\
\hline & $\mathrm{Hb}_{\mathrm{R}}, \mathrm{HbO}_{2}$ & $700-960$ & $\begin{array}{l}\text { Clinical flow-mediated dilatation } \\
\text { measurements }\end{array}$ & [17] \\
\hline & $\mathrm{HbO}_{2} \cdot \mathrm{Hb}_{\mathrm{R}}, \mathrm{SO}_{2}$ & $730,750,800,830$ & $\begin{array}{l}\text { Visualization of blood vessels, } \\
\text { microvasculature and the respective } \\
\text { oxygen saturation }\end{array}$ & [18] \\
\hline & $\mathrm{HbO}_{2}, \mathrm{Hb}_{\mathrm{R}}$, melanin & $730,760,790,820,850$ & $\begin{array}{l}\text { Real-time visualization of blood } \\
\text { vessels in 3D }\end{array}$ & {$[19,20]$} \\
\hline & $\mathrm{HbO}_{2}, \mathrm{Hb}_{\mathrm{R}}, \mathrm{SO}_{2}$ & 760,850 & $\begin{array}{l}\text { Movement correction and artifact-free } \\
\text { imaging }\end{array}$ & [21] \\
\hline & $\mathrm{HbO}_{2}, \mathrm{Hb}_{\mathrm{R}}$, melanin & $\begin{array}{l}700,720,740,760,780,800 \\
820,840,860\end{array}$ & Human angiography & {$[22,23]$} \\
\hline & $\mathrm{HbO}_{2}, \mathrm{Hb}_{\mathrm{R}}$ & $680-950,1064$ & Visualization of human carotid artery & [24] \\
\hline \multirow[t]{3}{*}{ Sentinel lymph node (SLN) } & Melanin, ICG & $700,730,760,800,850,900$ & Identification of SLNs & [25] \\
\hline & Melanin, ICG & $700,730,760,800,850$ & Metastatic status of lymph nodes & [26] \\
\hline & $\mathrm{Hb}$, methylene blue & 650,1064 & Identification of SLNs & [27] \\
\hline Inflammatory bowel disease & $\mathrm{Hb}_{T}, \mathrm{HbO}_{2}, \mathrm{Hb}_{\mathrm{R}}, \mathrm{SO}_{2}$ & $700,730,760,800,850,900$ & $\begin{array}{l}\text { Inflammatory disease activity in } \\
\text { Crohn's disease }\end{array}$ & {$[28,29]$} \\
\hline \multirow[t]{3}{*}{ Breast (cancer) } & $\mathrm{Hb}_{T}, \mathrm{HbO}_{2}, \mathrm{Hb}_{\mathrm{R}}, \mathrm{SO}_{2}$ & $700,730,760,800,850$ & $\begin{array}{l}\text { Characterization of healthy tissue } \\
\text { and malignant lesions }\end{array}$ & [30] \\
\hline & $\mathrm{HbO}_{2}, \mathrm{Hb}_{\mathrm{R}}$, water, lipid & 700-970 (10 nm steps) & & [31] \\
\hline & $\mathrm{HbO}_{2}, \mathrm{Hb}_{\mathrm{R}}$ & $730,760,850$ & & [32] \\
\hline \multirow[t]{4}{*}{ Thyroid } & $\mathrm{Hb}_{\mathrm{T}}, \mathrm{HbO}_{2}, \mathrm{Hb}_{\mathrm{R}}, \mathrm{SO}_{2}$, water, lipids & $\begin{array}{l}700,730,760,800,850 \\
900,920,950\end{array}$ & $\begin{array}{l}\text { Non-invasive diagnostics by tissue } \\
\text { characterization }\end{array}$ & [33] \\
\hline & - & - & Optical features of thyroid anatomy & [34] \\
\hline & $\mathrm{HbO}_{2}, \mathrm{Hb}_{\mathrm{R}}$, water, lipid & $760,850,930,970$ & $\begin{array}{l}\text { Differentiation between malignant } \\
\text { and benign thyroidal nodules }\end{array}$ & [35] \\
\hline & $\mathrm{HbO}_{2}$ & 1064 & $\begin{array}{l}\text { Photoacoustic/ultrasound dual } \\
\text { imaging of human thyroid cancer }\end{array}$ & [36] \\
\hline Systemic sclerosis & $\mathrm{Hb}_{\mathrm{T}}, \mathrm{HbO}_{2}, \mathrm{Hb}_{\mathrm{R}}$ & $700,730,750,800,850$ & Disease activity & [37] \\
\hline Muscle & $\mathrm{Hb}_{\mathrm{T}}, \mathrm{HbO}_{2}, \mathrm{Hb}_{\mathrm{R}}$, lipids, collagens & $\begin{array}{l}680,700,730,760,800,850 \\
920,1000,1030,1064,1100\end{array}$ & Disease extent in DMD patients & [38] \\
\hline
\end{tabular}

$\mathrm{Hb}_{\mathrm{R}}$ deoxygenated hemoglobin, $\mathrm{HbO}_{2}$ oxygenated hemoglobin, $\mathrm{Hb}_{T}$ total hemoglobin, $\mathrm{SO}_{2} \mathrm{MSOT}$-derived oxygen saturation

for deoxygenated hemoglobin $\left(\mathrm{Hb}_{\mathrm{R}}\right), 800 \mathrm{~nm}$ as measure for total hemoglobin (isosbestic point, $\mathrm{Hb}_{\mathrm{T}}$ ), and 850 $\mathrm{nm}$ for oxygenated hemoglobin $\left(\mathrm{HbO}_{2}\right)$.

When examining vasculature, MSOT is capable of visualizing major blood vessels and microvasculature [18]. As MSOT resolves hemoglobin in its oxygenated and deoxygenated states through optic absorption properties (whereas conventional Doppler ultrasound measures flow), it can also provide images of hemoglobin oxygen saturation and pulsation [18]. Successful studies were performed for mapping human feet blood vessels [18] as well as carotid arteries [24]. The ability to resolve vessels as small as $100 \mu \mathrm{m}$ in diameter and within 1-cm depth could also aid to diagnose vascular malformations [16].

In a consecutive study, the subcutaneous finger tissue of patients with systemic sclerosis (SSc) provided significantly lower MSOT values for oxygenated hemoglobin as well as total hemoglobin in comparison to healthy controls, reflecting microvascular dysfuntion in SSc as a possible marker of disease activity [37].

Further investigations explored the quantification of hemoglobin in the intestinal wall of patients with Crohn's disease (CD) with MSOT. These measures have been shown to be increased in patients with active $C D$, 
demonstrating robust correlation with endoscopic and microscopic intestinal inflammation [28]. MSOT could therefore be used to differentiate between active disease and remission in affected patients in a non-invasive fashion [29]. Its application is currently further explored in order to develop a clinically (CE) certified technology (www.euphoria2020.eu).

One of the main tissues examined with MSOT is breast tissue. In healthy breast tissue, hormone-related physiological changes of breast parenchyma were visualized with MSOT using only a three wavelengths illumination (700, 800, and $850 \mathrm{~nm}$ wavelengths) [39]. The authors found that intensity values were significantly higher at all excitation wavelengths in the secretory compared to the proliferative/follicular phase [39]. In malignant breast tissue, MSOT allowed the visualization of peripheral tumor vascularization, disruption of fat, and water tissue layers [31]. In addition, increased signals for hemoglobin were found in invasive breast cancer when compared to healthy breast tissue [30].

The high resolution in OAI/PAI makes it possible to reveal more vessels than with conventional Doppler as shown in a photoacoustic/ultrasound dual imaging study of human thyroid cancers [36]. While Doppler has sensitivity limits in terms of detecting movements/flow in small vessels, the precise visualization of hemoglobin containing tumor-related bloods vessels could improve cancer diagnosis [40], raising the hope to develop radiation-free screening technologies or treatment monitoring of other (solid) tumors for application in children.

In near-filed applications such as non-melanoma skin cancers MSOT already successfully distinguished skin cancer from normal skin, being helpful for the visualization of lesion margins [13, 14]. Even the detection of metastatic spread of melanoma to sentinel lymph nodes appears to be improved with MSOT when compared to current sentinel lymph node excision protocols $[25,26]$. Further, it was demonstrated that the injection of indocyanine green (ICG) and the detection via MSOT could be a proper replacement strategy for scintigraphy approaches [26].

Besides these promising first clinical studies, OAI has similar limitations like ultrasound. Namely, penetration depth of up to several centimeters as well as air, thick bones, body fat, and body hair can significantly influence image quality in adults. Therefore, children and adolescents might be excellent candidates for MSOT imaging as their organs and/or muscles are closer to the body surface.

Consequently, the first pediatric study showed that MSOT imaging is able to visualize the molecular composition of muscles in children. Muscular collagen content in children with Duchenne muscular dystrophy was increased as compared to healthy controls, suggesting non-invasive measured collagen content as a novel noninvasive biomarker for disease severity and potential monitoring tool for novel therapies [38]. Given the rise of genetic therapies, these findings underline the potential of MSOT for further personalized molecular imaging applications in children. A great advantage is that MSOT imaging can be performed without sedation or general anesthesia, which is especially important in patients with muscular disorders with respiratory depression. By using MSOT imaging, a substantial number of invasive procedures could hopefully be saved in the future.

\section{Limitations}

For translation into clinical practice, there are still several challenges to overcome: firstly, standardization of OAI imaging is required. It was already reported that preclinical OAI imaging systems consistently perform equal or even better (with variations smaller than 10\%) compared to other preclinical imaging modalities, which underlines their clinical potential [41]. In agreement with these findings, a small clinical study suggests that clinical MSOT provides consistent and reproducible results in humans as well [42]. For further validation, besides comparisons with other cross-sectional imaging modalities (US/MRI), prospective clinical trials with higher case number and multi-centric approaches with clinically meaningful outcomes are required. With the International Photoacoustic Standardization Consortium (IPASC), first efforts are currently made to facilitate an international debate and consensus to address this need [43]. Currently, there are two CE-marked OAI systems for clinical use: Imagio by Seno Medical Instruments and MSOT Acuity by iThera Medical GmbH. The high costs for OAI systems, especially when compared to current high-end ultrasound systems, are a main challenge for clinical implementation. Various approaches for reducing these costs are already in discussion, including alternate illumination sources and signal detection methods [44]. A higher number of commercially available systems might also help to reduce costs and allow a widespread adoption of MSOT in clinical practice.

\section{Future perspective}

MSOT is capable of visualizing endogenous chromophores such as hemoglobin, melanin, lipids, and recently collagens. Hemoglobin and collagens in particular display specific properties that are promising for monitoring the course of various diseases. Furthermore, the use of exogenous chromophores (e.g., optoacoustic targeted therapies) as contrast agents for OAI imaging in pediatric patients is still unexplored. Therefore, the combination of endogenous and exogenous molecular information could pave the way for novel tailored theranostic approaches in pediatrics in the future. 


\section{Abbreviations}

CD: Crohn's disease; DMD: Duchenne muscular dystrophy; exNIR: Extended near-infrared range; $\mathrm{HBO}_{2}$ : Oxygenated hemoglobin; $\mathrm{Hb}_{\mathrm{R}}$ : Deoxygenated hemoglobin; $\mathrm{Hb}_{\mathrm{T}}$ : Total hemoglobin; MPE: Maximum permissible exposure: MSOT: Multispectral optoacoustic tomography; NIR: Near-infrared range; OAl: Optoacoustic imaging; RUCT: Reflectance ultrasound computed tomography; $\mathrm{SaO}_{2}$ : MSOT-derived oxygen saturation

\section{Acknowledgements}

The present work was performed in (partial) fulfillment of the requirements for obtaining the degree "Dr. med." for ALW and in (partial) fulfillment of the requirements for obtaining the degree "Dr. rer. biol. hum." for FK.

\section{Authors' contributions}

APR, ALW, JC, MJW, and FK carried out the literature research. APR, ALW, and FK wrote the first draft of the manuscript. JC wrote the technological background section. The manuscript was critically reviewed by all authors. The author(s) read and approved the final manuscript.

\section{Authors' information}

Ferdinand Knieling has been working for 9 years in non-invasive preclinical and clinical imaging (ultrasound, CEUS, ultra-high frequency US, micro-CT, MSOT, RSOM). He has a dedicated scientific education in the field of ultrasound imaging (Prof. D. Strobel, Erlangen and Prof. J.-K. Willmann, Stanford, USA) and is the author of numerous leading publications in the field of optoacoustic imaging (New England Journal of Medicine, Nature Medicine, Gastroenterology). In 2019 he was awarded the Adalbert Czerny Prize by The German Society of Pediatrics and Adolescent Medicine (Deutsche Gesellschaft für Kinder- und Jugendmedizin - DGKJ) for "new diagnostics in pediatric medicine."

\section{Funding}

Else Kröner-Fresenius-Stiftung, Interdisciplinary Center for Clinical Research (IZKF) of the Friedrich-Alexander-University Erlangen-Nuremberg, and ELAN fund by the IZKF.

\section{Availability of data and materials}

Not applicable.

\section{Ethics approval and consent to participate}

Displayed patient data (Fig. 1) were acquired within approved study protocols by the local Ethical Review Board of the FAU Erlangen-Nuremberg and registered at clinicaltrials.gov (ID: NCT03490214, NCT02622139).

\section{Consent for publication}

Consent for publication was obtained.

\section{Competing interests}

APR and FK patent pending (EP 19163 304.9). APR and FK received travel support by iThera Medical GmbH, Germany. JC is an employee from iThera Medical GmbH, Germany.

\section{Author details \\ ${ }^{1}$ Pediatric Experimental and Translational Imaging Laboratory (PETI-Lab), Department of Pediatrics and Adolescent Medicine, \\ Friedrich-Alexander-University (FAU) Erlangen-Nuremberg, Loschgestraße 15, 91054 Erlangen, Germany. ${ }^{2}$ Medical Department 1, \\ Friedrich-Alexander-University (FAU) Erlangen-Nuremberg, Erlangen, Germany.}

\section{Received: 16 January 2020 Accepted: 24 February 2020}

\section{Published online: 04 March 2020}

\section{References}

1. Fenster ME, Hokanson JS (2018) Heart murmurs and echocardiography findings in the normal newborn nursery. Congenit Heart Dis. 13(5):771-775

2. Orman G, Benson JE, Kweldam CF, Bosemani T, Tekes A, de Jong MR et al (2015) Neonatal head ultrasonography today: a powerful imaging tool! J Neuroimaging. 25(1):31-55

3. Sharma R, Hudak ML (2013) A clinical perspective of necrotizing enterocolitis: past, present, and future. Clin Perinatol. 40(1):27-51
4. Aliev MM, Dekhqonboev AA, Yuldashev RZ (2017) Advantages of abdominal ultrasound in the management of infants with necrotizing enterocolitis. Pediatr Surg Int. 33(2):213-216

5. Knieling F, Waldner MJ, Goertz RS, Zopf S, Wildner D, Neurath MF et al (2013) Early response to anti-tumoral treatment in hepatocellular carcinoma--can quantitative contrast-enhanced ultrasound predict outcome? Ultraschall Med 34: 38-46

6. Claudon M, Dietrich CF, Choi BI, Cosgrove DO, Kudo M, Nolsøe CP et al (2013) Guidelines and good clinical practice recommendations for contrast enhanced ultrasound (CEUS) in the liver--update 2012: a WFUMB-EFSUMB initiative in cooperation with representatives of AFSUMB, AIUM, ASUM, FLAUS and ICUS. Ultraschall Med 34(1):11-29

7. Tzoumas S, Deliolanis N, Morscher S, Ntziachristos V (2014) Unmixing molecular agents from absorbing tissue in multispectral optoacoustic tomography. IEEE Trans Med Imaging 33(1):48-60

8. Taruttis A, Ntziachristos V (2015) Advances in real-time multispectral optoacoustic imaging and its applications. Nat Photonics. 9(4):219-227

9. Weber J, Beard PC, Bohndiek SE (2016) Contrast agents for molecular photoacoustic imaging. Nature Methods. 13(8):639-650

10. Ntziachristos $V$, Razansky D (2010) Molecular imaging by means of multispectral optoacoustic tomography (MSOT). Chem Rev. 110(5):27832794

11. Mercep E, Dean-Ben XL, Razansky D (2017) Combined pulse-echo ultrasound and multispectral optoacoustic tomography with a multisegment detector array. IEEE Trans Med Imaging 36(10):2129-2137

12. Mercep E, Jeng G, Morscher S, Li PC, Razansky D (2015) Hybrid optoacoustic tomography and pulse-echo ultrasonography using concave arrays. IEEE Trans Ultrason Ferroelectr Freq Control 62(9):1651-1661

13. Chuah SY, Attia ABE, Ho CJH, Li X, Lee JS, Tan MWP et al (2019) Volumetric multispectral optoacoustic tomography for 3-dimensional reconstruction of skin tumors: a further evaluation with histopathologic correlation. J Invest Dermatol. 139(2):481-485

14. Attia ABE, Chuah SY, Razansky D, Ho CJH, Malempati P, Dinish US et al (2017) Noninvasive real-time characterization of non-melanoma skin cancers with handheld optoacoustic probes. Photoacoustics. 7:20-26

15. Ford SJ, Bigliardi PL, Sardella TCP, Urich A, Burton NC, Kacprowicz M et al (2016) Structural and functional analysis of intact hair follicles and pilosebaceous units by volumetric multispectral optoacoustic tomography. J Invest Dermatol. 136(4):753-761

16. Masthoff M, Helfen A, Claussen J, Karlas A, Markwardt NA, Ntziachristos V et al (2018) Use of multispectral optoacoustic tomography to diagnose vascular malformations. JAMA Dermatol. 154(12):1457-1462

17. Karlas A, Reber J, Diot G, Bozhko D, Anastasopoulou M, Ibrahim T et al (2017) Flow-mediated dilatation test using optoacoustic imaging: a proofof-concept. Biomed Opt Express. 8(7):3395-3403

18. Taruttis A, Timmermans AC, Wouters PC, Kacprowicz M, van Dam GM, Ntziachristos V (2016) Optoacoustic imaging of human vasculature: feasibility by using a handheld probe. Radiology. 281(1):256-263

19. Dean-Ben X, Fehm TF, Razansky D (2014) Universal hand-held threedimensional optoacoustic imaging probe for deep tissue human angiography and functional preclinical studies in real time. J Vis Exp. 93: e51864

20. Dean-Ben XL, Ozbek A, Razansky D (2013) Volumetric real-time tracking of peripheral human vasculature with GPU-accelerated three-dimensional optoacoustic tomography. IEEE Trans Med Imaging 32(11):2050-2055

21. Dean-Ben XL, Bay E, Razansky D (2014) Functional optoacoustic imaging of moving objects using microsecond-delay acquisition of multispectral threedimensional tomographic data. Sci Rep 4:5878

22. Dean-Ben XL, Razansky D (2013) Functional optoacoustic human angiography with handheld video rate three dimensional scanner. Photoacoustics. 1(3-4):68-73

23. Dean-Ben XL, Razansky D (2013) Portable spherical array probe for volumetric real-time optoacoustic imaging at centimeter-scale depths. Opt Express. 21(23):28062-28071

24. Ivankovic I, Mercep E, Schmedt CG, Dean-Ben XL, Razansky D (2019) Realtime volumetric assessment of the human carotid artery: handheld multispectral optoacoustic tomography. Radiology. 181325

25. Stoffels I, Jansen P, Petri M, Goerdt L, Brinker TJ, Griewank KG et al (2019) Assessment of nonradioactive multispectral optoacoustic tomographic imaging with conventional lymphoscintigraphic imaging for sentinel lymph node biopsy in melanoma. JAMA Netw Open. 2(8):e199020 
26. Stoffels I, Morscher S, Helfrich I, Hillen U, Leyh J, Burton NC et al (2015) Metastatic status of sentinel lymph nodes in melanoma determined noninvasively with multispectral optoacoustic imaging. Sci Transl Med 7(317):317ra199

27. Garcia-Uribe A, Erpelding TN, Krumholz A, Ke H, Maslov K, Appleton C et al (2015) Dual-modality photoacoustic and ultrasound imaging system for noninvasive sentinel lymph node detection in patients with breast cancer Sci Rep 5:15748

28. Waldner MJ, Knieling F, Egger C, Morscher S, Claussen J, Vetter M et al (2016) Multispectral optoacoustic tomography in Crohn's disease: noninvasive imaging of disease activity. Gastroenterology. 151(2):238-240

29. Knieling F, Neufert C, Hartmann A, Claussen J, Urich A, Egger C et al (2017) Multispectral optoacoustic tomography for assessment of Crohn's disease activity. N Engl J Med. 376(13):1292-1294

30. Becker A, Masthoff M, Claussen J, Ford SJ, Roll W, Burg M et al (2018) Multispectral optoacoustic tomography of the human breast: characterisation of healthy tissue and malignant lesions using a hybrid ultrasound-optoacoustic approach. Eur Radiol 28(2):602-609

31. Diot G, Metz S, Noske A, Liapis E, Schroeder B, Ovsepian SV et al (2017) Multispectral optoacoustic tomography (MSOT) of human breast cancer Clin Cancer Res.

32. Dean-Ben XL, Fehm TF, Gostic M, Razansky D (2016) Volumetric hand-held optoacoustic angiography as a tool for real-time screening of dense breast. J Biophotonics. 9(3):253-259

33. Roll W, Markwardt NA, Masthoff M, Helfen A, Claussen J, Eisenblatter M et al (2019) Multispectral optoacoustic tomography of benign and malignant thyroid disorders - a pilot study. J Nucl Med.

34. Dima A, Ntziachristos V (2016) In-vivo handheld optoacoustic tomography of the human thyroid. Photoacoustics. 4(2):65-69

35. Dogra VS, Chinni BK, Valluru KS, Moalem J, Giampoli EJ, Evans K et al (2014) Preliminary results of ex vivo multispectral photoacoustic imaging in the management of thyroid cancer. AJR Am J Roentgenol. 202(6):W552-W558

36. Yang M, Zhao L, He X, Su N, Zhao C, Tang H et al (2017) Photoacoustic/ ultrasound dual imaging of human thyroid cancers: an initial clinical study. Biomed Opt Express. 8(7):3449-3457

37. Masthoff M, Helfen A, Claussen J, Roll W, Karlas A, Becker H et al (2018) Multispectral optoacoustic tomography of systemic sclerosis. J Biophotonics. 11(11):e201800155

38. Regensburger AP, Fonteyne LM, Jungert J, Wagner AL, Gerhalter T, Nagel AM et al (2019) Detection of collagens by multispectral optoacoustic tomography as an imaging biomarker for Duchenne muscular dystrophy. Nat Med. 25(12):1905-1915

39. Abeyakoon O, Morscher S, Dalhaus N, Ford SJ, Mendichovszky IA, Manavaki $R$ et al (2018) Optoacoustic imaging detects hormone-related physiological changes of breast parenchyma. Ultraschall Med

40. Toi M, Asao Y, Matsumoto Y, Sekiguchi H, Yoshikawa A, Takada M et al (2017) Visualization of tumor-related blood vessels in human breast by photoacoustic imaging system with a hemispherical detector array. Sci Rep. 7:41970

41. Joseph J, Tomaszewski MR, Quiros-Gonzalez I, Weber J, Brunker J, Bohndiek SE (2017) Evaluation of precision in optoacoustic tomography for preclinical imaging in living subjects. J Nucl Med. 58(5):807-814

42. Helfen A, Masthoff M, Claussen J, Gerwing M, Heindel W, Ntziachristos V et al (2019) Multispectral optoacoustic tomography: intra- and interobserver variability using a clinical hybrid approach. J Clin Med 8(1)

43. Bohndiek S (2019) Addressing photoacoustics standards. Nature Photonics 13(5):298

44. Fatima A, Kratkiewicz K, Manwar R, Zafar M, Zhang R, Huang B et al (2019) Review of cost reduction methods in photoacoustic computed tomography. Photoacoustics. 15:100137

\section{Publisher's Note}

Springer Nature remains neutral with regard to jurisdictional claims in published maps and institutional affiliations.

\section{Submit your manuscript to a SpringerOpen ${ }^{\circ}$ journal and benefit from:}

- Convenient online submission

- Rigorous peer review

- Open access: articles freely available online

- High visibility within the field

- Retaining the copyright to your article

Submit your next manuscript at $\boldsymbol{\nabla}$ springeropen.com 